\title{
Aplicação em subdose do haloxyfop-methyl na aveia-preta
}

\author{
Low doses of haloxyfop-methyl in black oat
}

\author{
Samir Paulo Jasper ${ }^{\mathrm{I}}$ Edivaldo Domingues Velini ${ }^{\mathrm{I}}$ Maria Rosecler Miranda Rossetto ${ }^{\mathrm{I}}$ \\ Caio Antônio Carbonari ${ }^{\mathrm{I}}$ Maria Lúcia Bueno Trindade ${ }^{\mathrm{I}}$
}

\section{RESUMO}

Uma das limitações para sustentabilidade do sistema de cultivo em plantio direto é a rápida decomposição da matéria seca. Um dos mecanismos conhecidos para minimizar este processo e potencializar a permanência da palhada no solo é alterar as vias metabólicas dos polímeros de lignina com aplicação de subdoses de herbicida, interferindo diretamente na resistência à degradação dos restos vegetais pelos microrganismos. Com este objetivo, o herbicida Verdict*R (haloxyfop-methyl) foi aplicado em subdoses nas plantas de aveia-preta e o efeito correlacionado com a altura das plantas, produtividade da matéria seca e metabolismo de lignina. Ensaios preliminares em casa de vegetação foram realizados para determinar as faixas de subdoses a serem aplicadas no experimento definitivo em campo. Os resultados obtidos demonstraram aumento de $24 \%$ na produtividade de matéria seca dos experimentos conduzidos em casa de vegetação com a aplicação de 3,125g do ingrediente ativo de haloxyfopmethyl por hectare (i.a. ha $a^{-1}$ ) nesta subdose, não foram observadas alterações na altura e no metabolismo de lignina nas plantas de aveia-preta. No campo, a concentração de 2,5g i. a. ha $a^{-1}$ do haloxyfop-methyl já foi suficiente para reduzir em 9\% a taxa de lignificação sem interferir na altura e produtividade das plantas, sendo este resultado favorável à velocidade de degradação da palhada no plantio direto.

Palavras-chave: Avena strigosa, haloxyfop-methyl, teor de lignina, estímulo de crescimento.

\section{ABSTRACT}

One of the major constraints to sustainable of the tillage is the rapid decomposition of dry the matter. One of the mechanisms known to facilitate this process is the interference in pathways of polymers of lignin from tests of application of low doses of herbicide based on the relation that higher the content of the lignin greater the resistance to degradation. With this purpose, the herbicide Verdict $* R$ (haloxyfop-methyl) was used to verify the effect of low doses at the height of the plants, productivity of dry matter and in the metabolism of the lignin in plants of black oat. Preliminary tests in the greenhouse were realized for adjustments to the best low doses to be applied in the definitive experiment in the production area. The results obtained were $24 \%$ of increase in productivity in the experiments conducted in greenhouse, from the application of $3.125 \mathrm{~g}$ of the active ingredient of the haloxyfopmethyl per hectare, in this subdose no changes was observed in growth and content of lignin in plants of black oat. In the field, the concentration of $2.5 \mathrm{~g} i$. a. ha $\mathrm{a}^{-1}$ of haloxyfop-methyl decreased in $9 \%$ the lignification rate without interfering with the height and productivity of the plants, this being favorable to the degradation rate of stubble tillage on outcome.

Key words: Avena strigosa, haloxyfop-methyl, levels of lignin, growth stimulus.

\section{INTRODUÇÃO}

A lignificação é um processo bioquímico que abrange a biossíntese de monolignóis, unidades básicas do polímero de lignina. A polimerização e o transporte destas subunidades são mediados por enzimas intrínsecas à formação de seus precursores nos compartimentos citoplasmáticos (ECKARDT, 2002). O estudo do processo de lignificação é um evento de alta importância no plantio direto com relação à taxa de decomposição do material incorporado ao solo, bem como a celulose e o acúmulo de nutrientes nestes resíduos (KOGELKNABNER, 2002). Estudos verificaram que quanto maior o teor de lignina e a relação $\mathrm{C} / \mathrm{N}$ nos resíduos vegetais, mais lenta será a sua taxa

INucleo de Pesquisas Avançadas em Matologia (NuPAM), Faculdade de Ciências Agronômicas (FCA), Universidade Estadual Paulista (UNESP), 18610-370, Botucatu, SP, Brasil. E-mail: roseclermiranda@yahoo.com.br. *Autor para correspondência. 
de decomposição (SAINJU et al., 2007). Devido estas correlações, a proteção do solo torna-se mais duradoura (FERREIRA et al., 2010). Trabalhos relataram que não apenas o conteúdo de carbono é responsável pela estabilidade da lignina contra oxidação química, mas também as interações da matéria orgânica e os minerais presentes na argila (CLEMENTE \& SIMPSON, 2013). Para TEIXEIRA et al. (2010), as gramíneas possuem maior relação $\mathrm{C} / \mathrm{N}$, razão de sua maior permanência no solo. Apesar da cultura de aveia-preta não possuir capacidade de fixar nitrogênio atmosférico, há grande interesse agronômico nesta espécie, devido ao baixo custo de produção, alta resistência às doenças e o rápido crescimento inicial, o que também favorece a cobertura do solo (CERETTA et al., 2002). O processo de alteração bioquímica nos teores de lignina pode ser verificado também pelo efeito de subdoses de herbicidas, resultando no mecanismo de dose-resposta distinguido por estimulação a baixa e inibição em altas dosagens. Esta relação tem características quantitativas bem determinadas e distintas, com faixas bem definida de limite entre o efeito estimulante e o de inibição (CALABRESE \& BLAIN, 2009).

$\mathrm{O}$ haloxyfop-methyl, empregado para o controle de plantas daninhas de folha estreita, utilizado em culturas de folha de larga, possui modo de ação interessante para a averiguação desse efeito. Até o momento, não há relatos científicos que correlacionem o metabolismo de lignina e a aplicação exógena de haloxyfop-methyl. Em doses específicas, esta molécula possui efeito herbicida, entretanto, em subdoses, pode ser metabolizado por determinadas espécies de plantas (RENDINA et al., 1990; TARDIF et al., 1996). O modo de ação do haloxyfop-methyl ocorre pelo bloqueio da síntese de lipídeos através da inibição da enzima Acetil-Coenzima A carboxilase (ACCase), comprometendo a primeira etapa da conversão de Acetil-Coenzima A (Acetil-CoA) para malonil-CoA. O malonil-CoA é uma substância precursora de metabólitos essenciais para estrutura celular e defesa das plantas, assim como síntese de flavonoides, ácidos graxos de cadeia longa e do etileno (SASAKI \& NAGANO, 2004). Entretanto, dependendo da subdose e do genótipo da planta, casos de resistência a estes herbicidas já foram constatados (RENDINA et al., 1990).

Devido à falta de dados na literatura e a importância do processo de preservação da lignina nas plantas, principalmente no plantio direto, este trabalho teve por objetivo verificar o efeito das subdoses do haloxyfop-methyl na biossíntese da lignina, no processo de desenvolvimento e no rendimento da matéria seca na cultura da aveia-preta.

\section{MATERIAL E MÉTODOS}

Os materiais utilizados nos ensaios foram sementes de aveia-preta (Avena strigosa Schreb. Var. Embrapa 139) e o herbicida comercial aplicado foi o Verdict*R (124,7 $\mathrm{g} \mathrm{L}^{-1}$ i. a. de haloxyfop-methyl) da Dow Agroscience. Os experimentos foram desenvolvidos nos períodos entre 2011 e 2012. O primeiro experimento (2011) foi realizado na casa de vegetação do Núcleo de Pesquisas Avançadas em Matologia da Faculdade de Ciências Agronômicas UNESP-Botucatu. O segundo experimento, realizado em 2012, foi desenvolvido na Fazenda de Ensino, Pesquisa e Extensão (FEPE) desta mesma faculdade.

$\mathrm{O}$ experimento em casa de vegetação foi realizado com o objetivo de selecionar as melhores doses do herbicida a serem utilizadas nos ensaios de campo, assim como preconizado por SCHRABERGER et al., (1999). O delineamento experimental adotado foi o inteiramente casualizado, com quatro repetições. Cada unidade experimental foi constituída de um vaso plástico $(5 \mathrm{~L})$ preenchidos com substrato Plant Max $^{\circledR}$. A semeadura foi realizada na densidade de $120 \mathrm{~kg}$ de sementes de aveia-preta por hectare, ou seja, cerca de $0,35 \mathrm{~g}$ de sementes por vaso. Os tratamentos constituíram-se da aplicação do herbicida haloxyfop-methyl adicionado de 0,5\% (v:v) do surfactante Aterbane nas subdoses: 3,125; 6,25 e $12,5 \mathrm{~g}$ i. a. ha ${ }^{-1}$ comparados às plantas testemunha. A aplicação foi realizada aos 28 dias após a semeadura (DAS) em plantas no estádio vegetativo de cinco folhas expandidas. O procedimento foi realizado com pulverizador estacionário acoplado a uma barra quatro pontas do tipo DG10 11002, com espaçamento entre os bicos de $0,5 \mathrm{~m}$ e posicionadas a $0,5 \mathrm{~m}$ de altura do alvo. O sistema foi operado com velocidade de deslocamento de $3,6 \mathrm{~km}$. $\mathrm{h}^{-1}$ a pressão constante de 1,5 bar e consumo de $200 \mathrm{~L} \mathrm{ha}^{-1}$ de volume de calda. A temperatura no momento da aplicação era de $25^{\circ} \mathrm{C}$, com umidade relativa do ar (UR) de 70\%.

$\mathrm{O}$ experimento de campo foi implantado entre as coordenadas $22^{\circ} 41^{\prime}$ 'Latitude Sul e $48^{\circ} 34^{\prime}$ de Longitude Oeste, com altitude média de $770 \mathrm{~m}$ e o clima classificado, segundo Koopler, como Cwb. Antecedendo a semeadura da aveia-preta, as culturas do triticale (Triticum triticosecale L.) e do milho (Zea mays L.), nos meses de junho e novembro de 2011, respectivamente, foram utilizadas para a formação de palha no local. A semeadura foi feita nas linhas com semeadora de precisão SEMEATO mod. 
SHM $15 / 17$ com densidade de $2 \mathrm{~g}$ por metro linear $\left(120 \mathrm{~kg} \mathrm{ha}^{-1}\right)$. O delineamento experimental adotado foi o em blocos ao acaso, com quatro repetições $(4 x 4)$. Cada unidade experimental (uma repetição) foi composta por plantas alocadas na área de $10 \mathrm{~m}$ de comprimento $\mathrm{x} 4 \mathrm{~m}$ de largura $\left(40 \mathrm{~m}^{2}\right)$, totalizando dezesseis parcelas. Os tratamentos foram compostos pela testemunha e pela aplicação de 0,$625 ; 1,25$ e $2,5 \mathrm{~g}$ i. a. ha $\mathrm{ha}^{-1}$ do herbicida adicionado de surfactante. Em cada parcela, foi mantida bordadura de $5 \mathrm{~m}$ ao fundo e $3 \mathrm{~m}$ ao lado, para evitar contaminação entre unidades. O experimento de campo ocorreu no mesmo período dos ensaios da casa de vegetação (28 DAS). A aplicação foi feita com pulverizador costal pressurizado com $\mathrm{CO}_{2}$ (1,96 bar), acoplado à barra de aplicação $(2 \mathrm{~m})$ interligada com quatro pontas Teejet XR 11002 VS e espaçadas entre si de $0,5 \mathrm{~m}$, com consumo de $200 \mathrm{~L}$. ha ${ }^{-1}$ de calda. A temperatura no momento da aplicação foi de $29{ }^{\circ} \mathrm{C}$ com UR de $90 \%$ e $15 \mathrm{~km} \mathrm{~h}^{-1}$ de velocidade do vento.

A medida da altura das plantas foi realizada aos 21 dias após a aplicação (DAA) nos ensaios da casa de vegetação (49 DAS). A amostragem foi feita em duas plantas por vaso por repetição (8 plantas por repetição) para cada tratamento. Em campo, a altura foi mensurada aos 98 DAA, ou seja, aos 119 DAS em 10 plantas (no metro linear) por repetição, nos tratamentos. As medidas foram realizadas com auxílio de uma trena, tomando como referência inicial o solo até a inserção da última folha totalmente expandida. A amostragem foi a mesma para as análises de matéria seca e lignina. Os materiais coletados foram pesados em balança de precisão $(0,001 \mathrm{~g})$, acondicionados em sacos de papel e submetidos à secagem em estufa de circulação forçada a $60^{\circ} \mathrm{C}$ (Marconi-MA-035/5), durante sete dias. Posteriormente, as plantas foram deixadas em dessecadores até temperatura ambiente e a matéria seca foi calculada a partir de novas pesagens para cada um dos tratamentos e convertida em produtividade de biomassa por vaso e parcela. As folhas secas foram combinadas em amostras compostas por repetição e foram finamente moídas em moinhos de rotor circular com facas (Marconi MA340).

A quantificação do teor de lignina foi realizada segundo o método de MORRISON (1977) com base na curva padrão de lignina (Sigma). Os dados obtidos foram submetidos à análise de regressão linear e quadrática com o auxílio do programa SigmaPlot (SYSTAT SOFTWARE, 2006), segundo metodologia de CEDERGREEN et al. (2005).

\section{RESULTADOS E DISCUSSÃO}

A altura média das plantas de aveiapreta utilizadas para a testemunha e as subdoses de 3,$125 ; 6,25$ e $12,5 \mathrm{~g}$ i. a. ha-1 de haloxyfop-methyl, no experimento conduzido em casa de vegetação aos 49 DAS, foram de 60,5;63; 58,5 e $18,33 \mathrm{~cm}$, respectivamente. Com a menor subdose, observouse estímulo do crescimento das plantas. Porém, até a concentração de $6,25 \mathrm{~g}$ i. a. ha ${ }^{-1}$ não houve alteração significativa do crescimento com relação ao controle. Observou-se que a subdose de $12,5 \mathrm{~g}$ i. a. ha ${ }^{-1}$ reduziu significativamente $(70 \%)$ este parâmetro, eliminando a utilização desta subdose no campo (Figura 1A). $\mathrm{O}$ modelo de predição ajustado para maximizar a altura da aveia-preta, de acordo com os dados preliminares obtidos em casa de vegetação, mostrou que a concentração de $2,74 \mathrm{~g}$ i. a. ha ${ }^{-1}$ seria suficiente para maximizar a altura das plantas em $64 \mathrm{~cm}$. Além disso, a predição demonstrou, ainda, que subdoses acima de $5,35 \mathrm{~g}$ i. a. ha $\mathrm{h}^{-1}$ iriam interferir negativamente no crescimento das plantas; estes dados foram corroborados pelas subdoses subsequentes (Figura 1A). A altura de plantas é uma variável bastante observada na literatura, principalmente com relação aos ensaios que relatam efeito de subdoses de herbicidas. Alguns exemplos foram notados em estudos realizados com a molécula de glyphosate (VELINI et al., 2008; SILVA et al., 2012).

Nos experimentos de campo, o modelo linear ajustado para descrever o perfil da altura das plantas aos 119 DAS nas subdoses de 0,625; 1,25; e $2,5 \mathrm{~g}$ i. a. ha ${ }^{-1}$ do haloxyfop-methyl não foi significativo com relação às plantas controle, não sendo observadas diferenças significativas entre os tratamentos (Figura 1B). Segundo SCHUCH et al.(2000), a cultura da aveia-preta é altamente susceptível ao acamamento, por isso fatores que contribuem para o aumento indesejado, assim como estímulo da adubação, efeito estimulante por aplicação de subdoses de herbicidas, etc., devem ser criteriosamente avaliados.

O modelo polinomial ajustado para analisar a produtividade de matéria seca da aveia-preta, em casa de vegetação (49 DAS), foi significativo e explicou acima de $94 \%$ que a produtividade da aveia-preta é influenciada pelo aumento das subdoses de haloxyfop-methyl. A predição relatou que a produtividade seria maximizada com a subdose de 2,3g i. a. ha ${ }^{-1}$ (Figura 2A). Considerando os valores médios obtidos experimentalmente, no tratamento controle, a produtividade foi de $7,45 \mathrm{~g}$ vaso $^{-1}$. Com relação à testemunha, foi possível obter incremento de $1,8 \mathrm{~g} \mathrm{vaso}^{-1}$ a partir da aplicação de $3,125 \mathrm{~g}$ i. a. ha ${ }^{-1}$ 


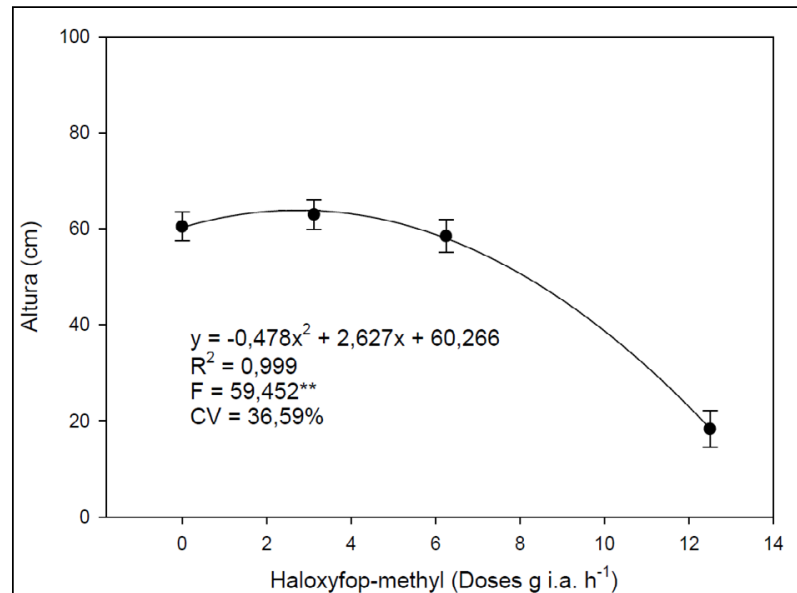

A

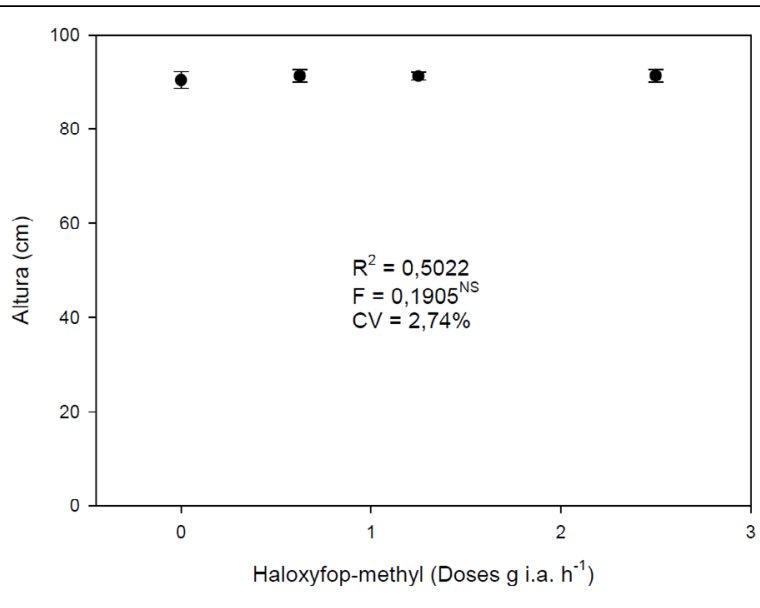

$\mathrm{B}$

Figura 1- Altura média (cm) das plantas de aveia-preta: A. Ensaios em casa de vegetação, avaliação aos 21 dias após aplicação (DAA) dehaloxyfop-methyl. B. Ensaiosobtidos no campo, avaliação aos 98 DAA dehaloxyfop-methyl. Os dados são referentes às médias \pm erro padrão $(\mathrm{n}=$ quatro repetições, dez leituras por repetição; $\mathrm{P}<0,01$ ).

do herbicida. Entretanto, as subdoses de 6,25 e $12,5 \mathrm{~g}$ i. a. ha ${ }^{-1}$ resultaram em reduções de 1,12 e $6,31 \mathrm{~g}$ vaso $^{-1}$ com relação à testemunha, respectivamente. Este dado contribuiu significativamente para descartar estas subdoses dos experimentos de campo (Figura 2A).

A produtividade no campo experimental, com base na biomassa de matéria seca aos 119 DAS foi de $27,53 \mathrm{~kg}_{40 \mathrm{~m}^{-2}}$ para plantas controle e 25,52;
25,97 e $22,73 \mathrm{~kg} 40 \mathrm{~m}^{-2}$ nas plantas que receberam 0,$625 ; 1,25$ e $2,5 \mathrm{~g}$ i. a. ha ${ }^{-1}$ de haloxyfop-methyl, respectivamente (Figura $2 \mathrm{~B}$ ). Estes ensaios resultaram em elevada produtividade quando comparada as utilizadas por KAEFER et al. (2012), que encontrou $6,33 \mathrm{~kg} 40 \mathrm{~m}^{-2}$ e próximos aos valores catalogados por MARTINS et al. (2008) que relataram $17,9 \mathrm{~kg} 40 \mathrm{~m}^{-2} \mathrm{de}$ produtividade, após 90 DAS. Com relação à aplicação do herbicida, o modelo polinomial linear resultou

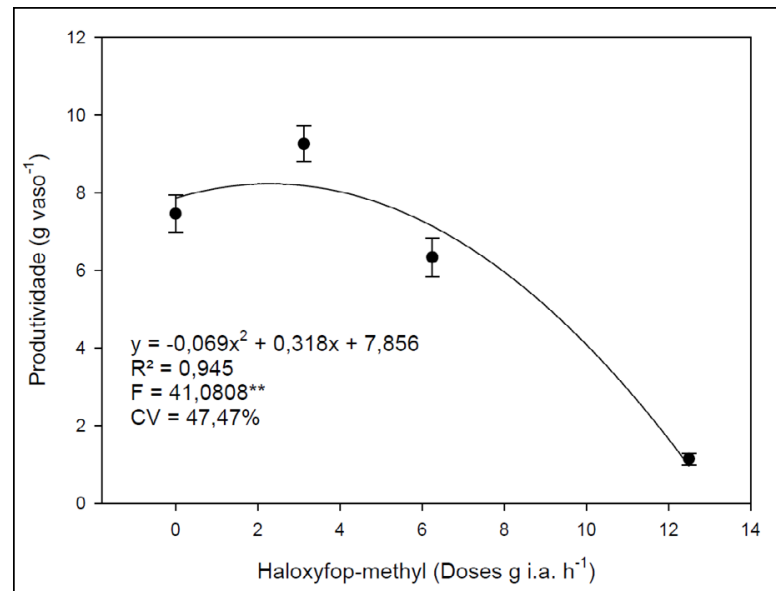

A

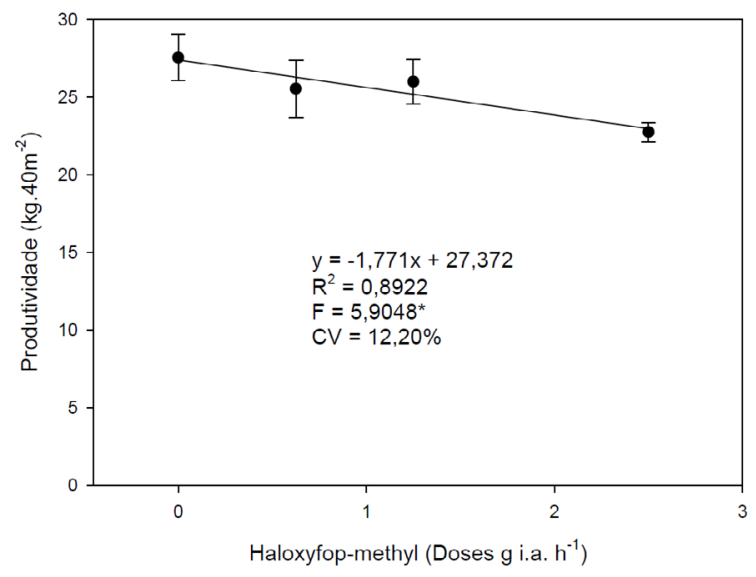

B

Figura 2 - Produtividade em plantas de aveia-preta. A. Ensaios realizados em casa de vegetação expressos em grama de peso seco vaso-1, com avaliação aos 21 DAA de haloxyfop-methyl. B. Ensaios obtidos no campo foram expressos em $\mathrm{Kg}$ de peso seco. $40 \mathrm{~m}-2$ com avaliação feita aos 98 DAA de haloxyfop-methyl. Os dados são referentes às médias \pm erro padrão $(\mathrm{n}=$ quatro repetições; quatruplicata de avaliação por repetição; $\mathrm{P}<0,01)$. 
em perfil de queda gradativa da produtividade, com concomitante aumento das subdoses de haloxyfopmethyl e consequente diminuição da permanência da palhada sobre o solo, estes resultados corroboram com os encontrados por TEIXEIRA et al. (2010).

Os teores médios de lignina no experimento desenvolvido em casa de vegetação resultaram em um perfil de aumento concomitante à concentração do herbicida. As subdoses de 3,125; 6,25 e 12,5g i. a. ha ${ }^{-1}$ forneceram teores médios de lignina de 7,21, 7,34 e $8,34 \%$, comparados a $6,88 \%$ encontrado nas plantas controle. A aplicação da subdose de $12,5 \mathrm{~g}$ i. a. ha ${ }^{-1}$ aumentou significativamente os teores de lignina teores de lignina, porém houve queda de $85 \%$ na produtividade com a aplicação desta subdose quando comparado às plantas controle, o que delimitou a escolha das concentrações ideais para serem experimentadas no campo (Figura 3A). O perfil de aumento de lignina encontrado foi um resultado interessante, já que vários autores verificaram que resíduos vegetais com maiores teores de lignina se decompõem mais lentamente quando comparados às plantas com menores teores, aumentando a permanência dos nutrientes no solo (SAINJU et al., 2007; OLIVEIRA et al.,2009; TEIXEIRA et al., 2010).

Ensaios no campo experimental, com subdoses de haloxyfop-methyl (controle; 0,625; 1,25 e $2,5 \mathrm{~g}$ i. a. ha $^{-1}$ ), resultaram nos teores médios de lignina de 6,$49 ; 6,05 ; 5,92$ e 5,89\%, respectivamente, ou seja, o ajuste linear predicto constatou redução significativa nos teores de lignina com relação às plantas controle (Figura 3B). Os teores de lignina da aveia-preta encontrados neste trabalho foram inferiores aos encontrados em Brachiaria decumbens, que mantiveram inalterados estes teores durante a aplicação de várias doses de glyphosate (MESCHEDE et al., 2011). Porém, o perfil desta substância, neste trabalho, corrobora o de cana-de-açúcar, que diminuíram os teores com a aplicação do mesmo herbicida (MESCHEDE et al., 2012). A regulação metabólica do processo de lignificação, apesar de ser uma característica genética peculiar de cada uma das plantas, pode ser manipulada tanto por fatores extrínsecos como também pela regulação dos genes correlatos a este metabolismo (SHI et al., 2012).

\section{CONCLUSÃO}

O aumento da produtividade com base na matéria seca foi de $24 \%$ nos experimentos conduzidos em casa de vegetação, com a aplicação da subdose de $3,125 \mathrm{~g}$ e. a. ha ${ }^{-1}$. Nesta concentração, não foram observadas alterações no crescimento e nos teores de lignina nas plantas de aveia-preta. No campo experimental, a subdose $2,5 \mathrm{~g}$ e. a. ha ${ }^{-1}$ do haloxyfop-methyl, apesar de reduzir em $9 \%$ a taxa de lignificação, mantiveram os teores de lignina favoráveis à velocidade de degradação da matéria seca no plantio direto, sem interferir na altura e na produtividade da aveia-preta deste experimento.

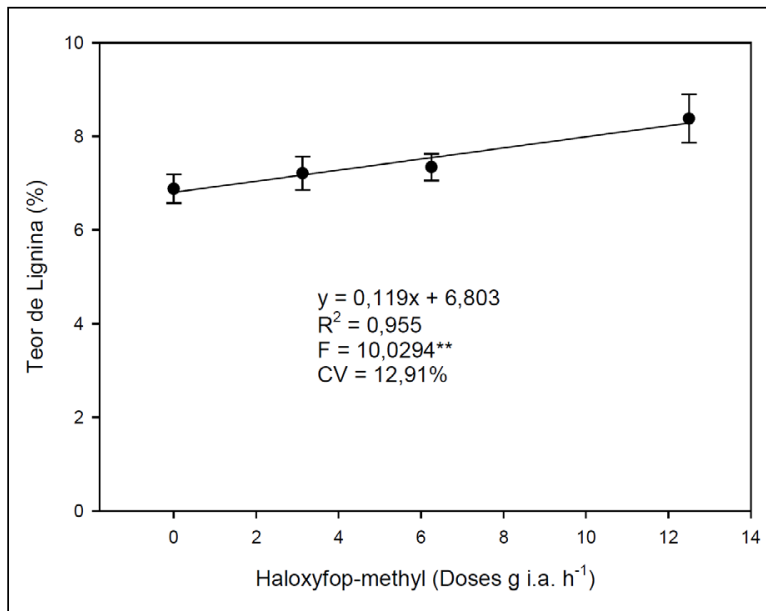

A

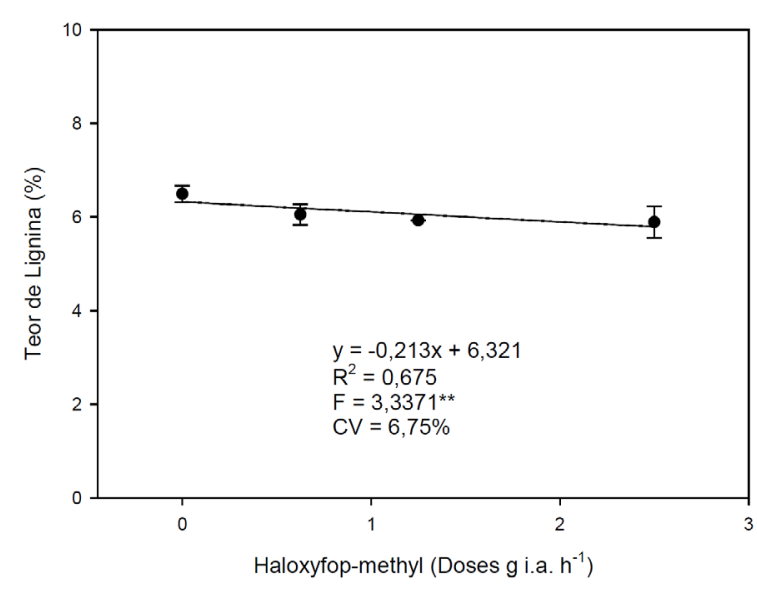

B

Figura 3 - Teor médio de lignina (\%) das plantas de aveia-preta: A. Ensaios realizados em casa de vegetação com avaliação aos 21 DAA de haloxyfop-methyl. B. Ensaios obtidos no campo com avaliação aos 98 DAA de haloxyfop-methyl. Os dados são referentes às médias \pm erro padrões $(\mathrm{n}=$ quatro repetições, quatruplicata de extração por repetição; $\mathrm{P}<0,01)$. 


\section{AGRADECIMENTOS}

Agradecemos ao apoio financeiro do Programa Nacional de Pós Doutorado da Coordenação de Aperfeiçoamento de Pessoal de Nível Superior (PNPD/CAPES). Processo auxílio: 2430.

\section{REFERÊNCIAS}

CALABRESE, E.J.; BLAIN, R.B. Hormesis and plant biology. Environmental Pollution, v.157, n.1, p.42- 48, 2009. Disponível em: $\quad<\mathrm{http} / /$ www.sciencedirect.com/science/article/pii/ S0269749108004077>. Acesso em: 19 set 2014. doi: 10.1016/j. envpol.2008.07.028.

CEDERGREEN, N. et al. Improved empirical models describing hormesis. Environmental Toxicology and Chemistry, v.24, n.12, p.3166-3172, 2005. Disponível em: <http://onlinelibrary.wiley. com/enhanced/doi/10.1897/05-014R.1/>. Acesso em: 19 set 2014. doi: 10.1897/05-014R.1.

CERETTA, C.A. et al. Manejo da adubação nitrogenada na sucessão aveia preta/milho, no sistema plantio direto. Revista Brasileira de Ciência do Solo, v.26, n.1, p.163-171, 2002. Disponível em: $<$ http://www.scielo.br/pdf/pab/v38n1/a17v38n1.pdf >. Acesso em: 19 set 2014. doi: 10.1590/S0100-204X2003000100017.

CLEMENTE, J. S.; SIMPSON, M. J. Physical protection of lignin by organic matter and clay minerals from chemical oxidation. Organic Geochemistry, v.58, p.1-12, 2013. Disponível em: $<$ http://www.sciencedirect.com/science/article/pii/ S014663801300034X>. Acesso em: 19 set 2014. doi: 10.1016/j. orggeochem.2013.02.007.

ECKARDT, N.A. Probing the mysteries of lignin biosynthesis: the crystal structureof caffeic acid/5-hydroxyferulic acid 3/5-O-methyltransferase provides new insights. Plant Cell, v.14, n.6, p.1185-1189, 2002. Disponível em: $<$ http://dx.doi.org/10.1105/ tpc.140610>. Acesso em: 19 set 2014. doi: 10.1105/tpc.140610.

FERREIRA, A.C.B. et al. Produção de biomassa por cultivos de cobertura do solo e produtividade do algodoeiro em plantio direto. Pesquisa Agropecuária Brasileira, v.45, n.6, p.546553, 2010. Disponível em: <http:/www.scielo.br/pdf/pab/v45n6/ a03v45n6.pdf>. Acesso em: 19 set 2014. doi: 10.1590/S0100204X2010000600003.

KAEFER, J.E. et al. Influência das épocas de manejo químico da aveia-preta sobre a incidência de plantas daninhas e desempenho produtivo do milho. Semina: Ciências Agrárias, v.33, n.2, p.481490, 2012. Disponível em: <http://www.uel.br/revistas/uel/index. $\mathrm{php} / \mathrm{semagrarias} /$ article/view/6156/10470>. Acesso em: 19 set 2014. doi: 10.5433/1679-0359.2012v33n2p481.

KOGEL-KNABNER, I. The macromolecular organic composition of plant and microbial residues as inputs to soil organic matter. Soil Biology \& Biochemistry, v.34, n.2, p.139-162, 2002. Disponível em: <http://www.sciencedirect.com/science/article/ pii/S0038071701001584>. Acesso em: 19 set 2014. doi: 10.1016/ S0038-0717(01)00158-4.

MARTINS, J.D. et al. Influência da densidade e velocidade de semeadura no crescimento da aveia preta (Avena strigosa Schreb.), em semeadura direta. Pesquisa Agropecuária Gaúcha, v.14, n.1, p.33-40, 2008. Disponível em: <http://www.fepagro.rs.gov.br/ upload/1398792507_art05.pdf>. Acesso em: 19 set 2014.
MESCHEDE, D.K. et al. Teores de lignina e celulose em plantas de cana-de-açúcar em função da aplicação de maturadores. Planta Daninha, v.30, n.1, p.121-127, 2012. Disponível em: <http://www.scielo.br/scielo.php?pid=S0100$83582012000100014 \&$ script $=$ sci arttext $>$. Acesso em: 19 set 2014. doi: 10.1590/S0100-83582012000100014

MESCHEDE, D.K. et al. Efeitos do glyphosate nos teores de lignina, celulose e fibra em Brachiaria decumbens. Revista Brasileira de Herbicidas, v.10, n.1, p.57-63, 2011. Disponível em: <http://www. rbherbicidas.com.br/index.php/rbh/article/view/77/pdf $>$. Acesso em: 19 set 2014. doi: 10.7824/rbh.v10i1.77.

MORRISON, I.M. A semi-micro method for the determination of lignin and its use in predicting the digestibility of forage crops. Journal of the Science of Food and Agriculture, v.23, n.4, p.455-463, 1977. Disponível em: <http://onlinelibrary.wiley.com/ doi/10.1002/jsfa.2740230405/pdf>. Acesso em: 19 set 2014.

OLIVEIRA, M.B. et al. Teor de lignina em plantas de Eucalyptus urophylla S. T. Blake tratadas com fitorreguladores. Silva Lusitana, v.17, n.1, p.51-57, 2009. Disponível em: <http://www. scielo.oces.mctes.pt/pdf/slu/v17n1/v17n1a04.pdf>. Acesso em: 19 set 2014. doi: 10.1002/jsfa.2740230405.

RENDINA, A.R. et al. Inhibition of acetyl-coenzyme a carboxylase by two classes of grass-selective herbicides. Journal of Agricultural and Food Chemistry, v.38, n.5, p.1282-1287, 1990. Disponível em: <http://pubs.acs.org/doi/abs/10.1021/ jf00095a029>. Acesso em: 19 set 2014. doi: 10.1021/jf00095a029.

SAINJU, U.M. et al. Cover crop effect on soil carbon fractions under conservation tillage cotton. Soil and Tillage Research, v. 96, n.1-2, p.205-218, 2007. Disponível em: <http://www. sciencedirect.com/science/article/pii/S0167198707001109>. Acesso em: 19 set 2014. doi: 10.1016/j.still.2007.06.006.

SASAKI, Y; NAGANO, Y. Plant acetyl-CoA carboxylase: structure, siosynthesis, regulation and gene manipulation for plant breeding. Bioscience Biotechnology and Biochemistry, v. 68 , n.6, p.1175-1184, 2004. Disponível em: < https://www.jstage.jst.go.jp/ article/bbb/68/6/68 6 1175/article>. Acesso em: 19 set 2014. doi: $10.1271 / \mathrm{bbb} \cdot \overline{\overline{8}} \cdot \overline{1175}$.

SCHABENBERGER, O. et al. Statistical tests for hormesis and effective dosage in herbicide dose response. Agronomy Journal, v.91, n.4, p.713-721, 1999. Disponível em: <https://www.crops. org/publications/aj/abstracts/91/4/713>. Acesso em: 19 set 2014. doi: 10.2134/agronj1999.914713x

SCHUCH, L.O.B. et al. Emergência no campo e crescimento inicial de aveia preta em resposta ao vigor das sementes. Revista Brasileira de Agrociência, v.6, n.2, p.97-101, 2000. Disponível em: <http://periodicos.ufpel.edu.br/ojs2/index.php/CAST/article/ viewArticle/326>. Acesso em: 19 set 2014

SHI, H. et al. Overexpression of cotton (Gossypium hirsutum) dirigent 1 gene enhances lignifications that blocks the spread of Verticillium dahlia. Acta Biochimica et Biophysica Sinica, v.44, n.7, p.555-564, 2012. Disponível em: <http://www.readcube.com/ articles/10.1093/abbs/gms035>. Acesso em: 19 set 2014. doi: 10.1093/abbs/gms035.

SILVA, J.C. et al. Efeito hormese de glyphosate em feijoeiro. Pesquisa Agropecuária Tropical, v.42, n.3, p.295-302, 2012. Disponível em: <http://www.scielo.br/pdf/pat/v42n3/ 
a07v42n3.pdf>. Acesso em: 19 set 2014. doi: 10.1590/S198340632012000300008 .

SYSTAT SOFTWARE Inc - SSI. Sigmaplot for Windows, version 10, 2006. Disponível em: <http://www.systat.com.products/ sigmaplot>. Acesso em: 17 ago. 2013.

TARDIF, F.J. et al. Resistance to acetyl-coenzyme a carboxylaseinhibiting herbicides endowed by a single major gene encoding a resistant target sitein a biotype of Lolium rigidum. Australian Journal Plant Physiology, v.23, p.15-23, 1996. Disponível em: $<$ http://www.publish.csiro.au/paper/PP9960015.htm>. Acesso em: 19 set 2014. doi: 10.1071/PP9960015.
TEIXEIRA, C.M. et al. Liberação de macronutrientes das palhadas de milheto solteiro e consorciado com feijão-deporco sob cultivo de feijão. Revista Brasileira de Ciência do Solo, v.34, n.2, p.497-505, 2010. Disponível em: <http://www. scielo.br/scielo.php?pid=S0100-32010000200023\&script $=$ sci abstract\&tlng=pt. Acesso em: 19 set 2014. doi: $0.1590 / \mathrm{S} 0100-$ 06832010000200023.

VELINI, E.D. et al. Glyphosate applied at low doses can stimulate plant growth. Pest Management Science, v.64, n.4, p.489-496, 2008. Disponível em: <http://www.bioone.org/doi/full/10.1614/ WS-D-09-00028.1>. Acesso em: 19 set 2014. doi: 10.1614/WS-D09-00028.110.2134/agronj1999.914713x. 